\title{
A REESTRUTURAÇÃO PÓS-FORDISTA DA PRODUÇÃO E SUAS CONSEQÜENCIAS SOBRE AS NOVAS FORMAS DE GESTÃO DE PROJETOS NA INDÚSTRIA AUTOMOBILÍSTICA BRASILEIRA: O CASO DA FIASA - FIAT AUTOMÓVEIS S.A.
}

\section{THE POST-FORDIST RESTRUCTURING OF PRODUCTION AND ITS CONSEQUENCES IN THE NEW FORMS OF PROJECT MANAGEMENT IN THE BRAZILIAN AUTO INDUSTRY: THE CASE OF FIASA - FIAT AUTO S.A.}

\author{
Luís Antônio Cardoso ${ }^{1}$ \\ ${ }^{1}$ Professor da Universidade Estadual do Norte Fluminense \\ lac@uenf.br
}

Recebido para publicação em: 19/02/2005 Aceito para publicação em: 25/06/2005

\section{RESUMO}

Este trabalho tem como objetivo a análise das transformações sobre a atividade de gestão de projetos em uma empresa da indústria automobilística brasileira a partir do processo de reestruturação pós-fordista.

Palavras-Chave: Gerência da Produção, Gestão por Projetos, Meta-Regras, Pós-Fordismo

\section{Introdução}

O advento do novo modelo produtivo, que ora denominamos "pós-fordismo", ou em outras palavras, de "era pós-fordista", no qual o sistema JIT constitui-se como um dos seus mais importantes princípios produtivos, tem trazido importantes modificações na forma como as empresas lidam com a gestão de seus processos produtivos.

Seja no desenvolvimento de novos produtos ou serviços, bem como nas ações de reestruturação da empresa através dos novos modelos produtivos e das novas ferramentas de gestão, os projetos internos às organizações passam a serem vistos como um fator altamente estratégico para a empresa.

Assim, pode-se dizer seguramente que, a organização produtiva dos processos de fabricação, devido a grande necessidade de flexibilização da organização face à aceleração do ritmo das mudanças tem se tornado, o lugar por excelência dos projetos, ou da gestão por projetos. É 
nesse sentido, pois que podemos também dizer que nesses novos modelos produtivos que surgem com a era pós-fordista, as empresas, de modo diferente dos paradigmas produtivos precedentes, tornam-se empresas orientadas a projeto.

Este artigo tem como objetivo analisar essa complexa passagem, tomando como ilustração a indústria automobilística brasileira. Para tal empreitada, colocamos no centro de nossa análise um dos casos mais representativos da reestruturação pós-fordista do setor automobilístico, qual seja, a empresa FIASA - Fiat Automóveis S.A.

Em princípio faremos uma breve discussão teórica do processo de transformação da gestão de projetos, evidenciando a tese segundo a qual, nessa nova era pós-fordista, os projetos internos da empresa assumem um papel de suma importância para o seu desenvolvimento estratégico.

Em seguida, faremos uma análise do processo de transformação da FIASA - Fiat Automóveis S.A., ilustrando como a empresa realiza essa difícil transição e assume essa nova cultura dos projetos como um dos eixos de seu processo de modernização e desenvolvimento.

\section{O pós-fordismo e a mudança de paradigmas na gestão de projetos}

As modificações que surgem com a mudança de paradigma, isto é, da passagem do taylorismo-fordismo para o pós-fordismo, em relação à gestão de projetos, de um modo geral, concentram-se em torno de dois grandes eixos:

1. A aplicação da idéia de concorrência ou de simultaneidade, isto é de aplicação dos princípios da engenharia simultânea (concurrent engineering) a um número crescente de projetos internos, e;

2. A idéia, segundo a qual o sucesso dos projetos está cada vez menos condicionado ao rigor do planejamento e ao emprego de ferramentas sofisticadas (tais como o WBS - Work Breakdown Structure, Pert, CPM, Gantt e outras), mas sim, cada vez mais, à flexibilidade da organização em termos da autonomia dos atores e à qualidade do sistema de relações interpessoais e comunicação.

Quanto à primeira categoria de mudança - o interesse pela concorrência -, observa-se que esta, quando aplicada ao desenvolvimento dos projetos nas empresas tende a substituir o tradicional princípio lógico e mecanicista da ordem seqüencial dos projetos, por um princípio social do envolvimento, da participação dos membros da empresa, em projeto, desde a sua origem. Reitera-se a idéia de que o princípio da concorrência envolve, cria um clima de engajamento entre os membros da organização, além de fomentar o diálogo necessário desde o princípio da atividade projetual. Essa categoria de mudanças, por sua vez, torna a introdução de equipes pluridisciplinares como algo essencial a esse novo paradigma. Desse modo, as questões de ordem estratégica da produção, a reinvenção dos processos, os sistemas de informação, e os problemas de transição organizacional, em específico o da condução da mudança do paradigma tecnológico, passam a levar em conta os 
aspectos humanos e sociais da produção. Por outro lado, as práticas de reengenharia que acompanham todo esse processo, as quais também se apóiam sobre a idéia de concorrência, revolucionam, em mesmo grau, a condução dos projetos, bem como a sua ordenação seqüencial.

A segunda categoria de mudanças, que diz respeito à importância da flexibilidade e da autonomia no sucesso dos projetos, traz também importantes mudanças na organização estrutural dos projetos. Em um outro trabalho, Clark, Hayes e Wheelwright (1988) ressaltam esse caráter da flexibilidade estrutural, afirmando que a maior probabilidade de sucesso dos projetos tende a ser maior quanto mais as organizações tendem a se aproximar da configuração das estruturas de tipo externalizado (tiger team organizations), isto é, as configurações do tipo 4 (vide Figura 1). Todavia a maior conseqüência dessa transformação estaria na ordem do desenvolvimento de projetos com um caráter horizontal, temporário, e autônomo em relação à estrutura da empresa.

Por outro lado, essa configuração horizontal de projeto, além de sua natureza flexível e autônoma, teria como conseqüência maior todo um conjunto de ações, assim definidas como metaregras, que implicariam em uma complexa transformação da organização da empresa. Sob esse ponto de vista, Jolivet (1993) sustenta que a partir dessa perspectiva cada projeto deve definir suas próprias regras, sua organização, sua atribuição de responsabilidades, além de escolher suas próprias ferramentas, pois senão, sem a auto-organização os projetos estariam sujeitos a disfunções graves - tais como, a falta de reatividade, a mediocridade das decisões, a burocracia emperrada, as dificuldades de controle da complexidade, além de outras.

Desse modo, esta auto-organização faz-se necessária, uma vez que ela se inscreve em um quadro global que se apóia sobre a experiência adquirida na organização. Logo, na visão do autor, esta é a função das meta-regras: regras que produzem as regras, e que se caracterizam como regras globais que permitem produzir de maneira coerente, eficaz, descentralizada as regras do projeto em toda a sua extensão. Destarte, pode-se dizer que essas meta-regras advindas com essa nova forma de gestão de projetos constitui-se como uma alternativa ao modelo tradicional do taylorismo/fordismo, o qual baseava-se pela existência de procedimentos padronizados, de ferramentas sofisticadas de gestão e a preeminência da organização permanente a qual definia as responsabilidades, a alocação dos recursos, e as regras de organização e de gestão.

As meta-regras, de um modo geral, são definidas em número de dezessete, sendo doze delas centradas sobre a gestão e cinco outras sobre os princípios de organização (Quadro 1).

\begin{tabular}{|l|l|}
\hline Organização Clássica & Auto-Organização à partir das Meta-Regras \\
\hline Organização Permanente & Organização Evolutiva e Temporária \\
\hline Estruturação Piramidal e Funcional das Tarefas & Organização Celular \\
\hline Padronização dos Procedimentos & Meta-Regras e Regras Específicas \\
\hline $\begin{array}{l}\text { Responsabilidades Fracionadas de modo } \\
\text { Vertical e Horizontal }\end{array}$ & $\begin{array}{l}\text { Responsabilidades Repartidas e Empowerment } \\
\text { dos Indivíduos }\end{array}$ \\
\hline Controle pelo Acompanhamento das Falhas & Controle sobre a Ênfase no Sucesso \\
\hline Massificação dos Problemas sobre o Indivíduo & Direito e Respeito às Diferenças de Opinião \\
\hline
\end{tabular}


Fonte: JOLIVET, François. op. cit. 1993.

Quadro 1 - Diferenças básicas entre a organização clássica e a auto-organização definida pelas meta-regras

Estrutura Funcional (Functional Organization)

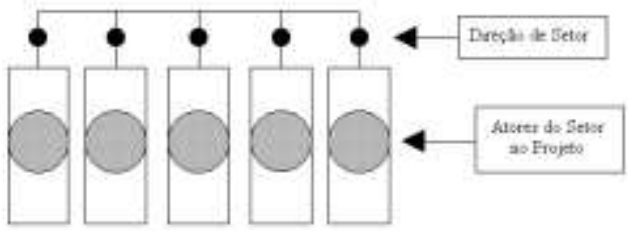

o Coordenador de Projeto (Lightweight Project Manager

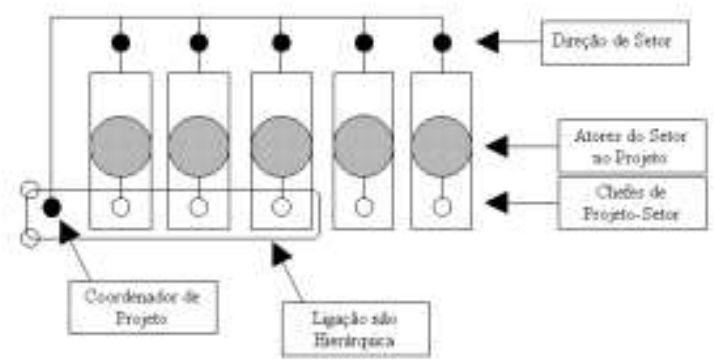

O Diretor de Projeto (Heasyweight Project Manager)

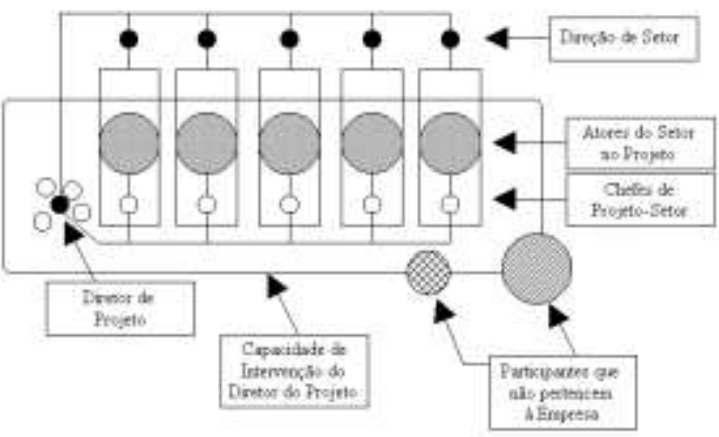

O Projeto Externalizado (Tiger Team Organization)

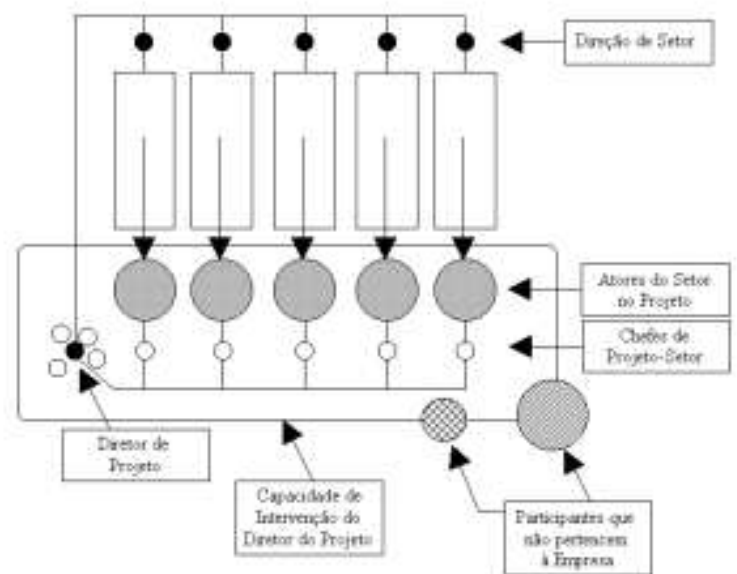

Fonte: CLARK, K.B.; HAYES, R.H.; \& WHEELRIGHT, S.C., 1988.

Figura 1 - Configurações de projetos em relação às funções permanentes ou setores 
No tocante as meta regras de gestão, essas compreendem as atividades de compras, o material, a subcontratação, a fabricação, a qualidade, os custos, os prazos, os recursos humanos, as relações com o cliente, além do domínio do savoir-faire da organização.

Por outro lado, as outras meta-regras que abarcam as funções de organização (ver Quadro 1), estabelecem que a autonomia do projeto é total, pois cabe ao chefe do projeto a definição de seus objetivos, as suas políticas, sua organização, a escolha de seus colaboradores bem como suas relações com os subcontratantes e com a empresa permanente.

Em relação aos projetos, essas meta-regras implicam para a organização da empresa o seu desenvolvimento em divisão celular, o qual, por sua vez, incorpora as diferentes funções em um responsável o qual define seus objetivos em conformidade com os objetivos gerais do projeto. Ainda, o conjunto dessas meta-regras indica a capacidade do projeto de dispor de meios próprios, que os serviços permanentes terão uma relação do tipo cliente-fornecedor com o projeto, e que o chefe de projeto deverá tornar explícito seus objetivos e políticas, bem como os princípios de organização e de gestão.

Assim sendo, percebe-se que essas transformações têm a propriedade de transformar a tradicional gestão de projetos em um processo, assimilando-a a uma atividade temporária. É nesse sentido que Joly \& Muller (1994), afirmam que esse novo paradigma tem o caráter de forçar a inserção de uma nova cultura no setor. Mais ainda, os autores sustentam a tese de que essa nova cultura, esse novo paradigma, tem a capacidade de provocar uma mudança radical nos processos gestionários, fazendo com que as empresas passem de um velho paradigma de gestão de projetos a um novo paradigma de gestão por projetos.

É nesse sentido, pois, que essas transformações, essa alternância de paradigma, vai ser caracterizada como uma mudança de tipo revolucionário, colocando as organizações como unidades altamente flexíveis e adaptáveis a qualquer contingência ou desequilíbrio do ambiente na qual se inserem.

Doravante, passamos a descrever o caso de uma das maiores empresas automobilísticas brasileiras, a FIASA - Fiat Automóveis S.A., na qual a inserção desse novo modelo flexível de gestão por projetos teve uma posição de destaque na passagem do velho paradigma fordista para o novo paradigma pós-fordista.

\section{O caso da FIASA - FIAT automóveis S.A.}

A FIASA - Fiat Automóveis S.A. constitui-se como uma das empresas do Grupo FIAT, da Itália, dedicada à atividade de fabricação de veículos, especialmente de automóveis. 
A empresa foi criada no Brasil em 1973 como uma alternativa à crise européia do fordismo, entrando plenamente em funcionamento no ano de 1976.

Ao longo de seus primeiros anos de funcionamento no Brasil, desde os anos 70, a preocupação dessa empresa centrou-se na constituição de um regime produtivo fordista tradicional, organizado em torno da linha de montagem de veículos ou, mais precisamente, na fabricação do modelo 147 ou, do Projeto 147.

A partir de 1989, após as sucessivas crises e do fracasso da tentativa de substituir o modelo fordista-taylorista tradicional de racionalização estabelecido em suas fábricas, o Grupo FIAT decide promover a reestruturação de todas as suas fábricas através da introdução de um novo regime pósfordista.

As transformações na Itália, tanto quanto no Brasil, iniciam-se no final dos anos 80 a partir das determinações da direção do Grupo FIAT acordadas na célebre Convenção de Marentino, na qual a Direção da empresa, adotando o mote "fare comme in Giaponne" (fazer igual aos japoneses), assume o compromisso de reestruturar todas as suas fábricas segundo os padrões utilizados pelo modelo japonês de produção.

Assim, o ano de 1989 foi definido como o ano da mudança da FIASA em Betim. Após as conversões das fábricas italianas, o Grupo FIAT decide implantar o modelo de inspiração ohnoísta no Brasil. O modelo da azienda corta (fábrica enxuta) pensado pela matriz é então difundido e posto em prática na sua maior filial, tanto quanto uma experiência ou modelo híbrido, isto é, fundindo inúmeros princípios produtivos pós-fordistas e não somente originalmente japoneses. A idéia da fábrica enxuta, a qual é originalmente difundida na Itália como Fabbrica Integrata (Fábrica Integrada) assume, no Brasil, a nomenclatura de Fábrica Racionalizada. De um certo modo, esse novo conceito colocará em prática algumas das mais importantes transformações tanto na estrutura global da empresa, quanto nas estruturas da organização produtiva e na relação salarial.

A intenção da nova empresa enxuta foi a de criar uma estrutura mais horizontal, mais flexível e em consonância com os novos modelos produtivos mundiais. De modo quase idêntico aos transplantes da lean production no mundo, a fábrica de Betim procurou um modelo no qual a organização produtiva caracterizou-se pela introdução de um conjunto de ferramentas de gestão próprias aos novos modelos produtivos híbridos, destacando-se: o funcionamento integrado da fábrica, a engenharia simultânea, a gestão da qualidade total, o sistema JIT, o sistema kanban, o kaizen, a TPM, a gestão por processos, a manufatura celular, dentre outros.

No que diz respeito à organização produtiva da fábrica, a reestruturação introduziu todo um conjunto de princípios produtivos, caracterizados pelo desenvolvimento da integração sócio-técnica da firma. Por outro lado, no que diz respeito ao processo de organização do trabalho da fábrica, este é visto como outro ponto de vital importância, visto que ele assume um papel fundamental em todo 
o processo de transformação da empresa, ampliando consideravelmente o grau de flexibilidade do trabalho ou, mais precisamente, de flexibilização da força de trabalho.

Um outro conjunto de transformações que se pode observar nesse processo de reconstrução da organização produtiva pós-fordista, também oriundo das implicações desses novos princípios produtivos, em específico do sistema JIT, e que nós analisamos nesse trabalho, diz respeito à mudança no tipo da gestão e do controle dos projetos industriais, ou seja, dos projetos que dão conta da realização do produto final do setor automobilístico, o carro.

Observa-se que, na velha fábrica fordista de Betim, tal como nas correspondentes italianas, que se estruturavam segundo a lógica da firma taylorista/fordista, o mecanismo de orientação de gestão e de realização dos projetos do automóvel repousava sobre uma visão estritamente funcional e fortemente hierarquizada e de caráter permanente. A esse modelo, correspondia uma determinada forma ou estrutura de projeto, assim denominada de fast-track (Figura 2).

Concebida sob a forma matricial, essa estrutura de gestão procurava ordenar o projeto de produção de um veículo segundo as fases básicas de desenvolvimento (pesquisa, pré-projeto, desenvolvimento, industrialização e exploração) e os atores envolvidos (pesquisa, marketing final, design, centro de estudos, engenharia, compras, fornecedores, fabricação e vendas). Seu funcionamento, além de apresentar uma forte característica mecânica, baseava-se em um forte planejamento e no uso sofisticado de ferramentas de controle de projeto (PERT/CPM, Gráficos de Gantt, etc...). Ainda, era relegado a um chefe, que participava de sua execução baseando-se nos trabalhos de definição do pré-projeto. Esse método de gestão, incorporava uma certa integração entre os atores na medida em que somente era possível executar simultaneamente as tarefas segundo uma seqüência pré-determinada.

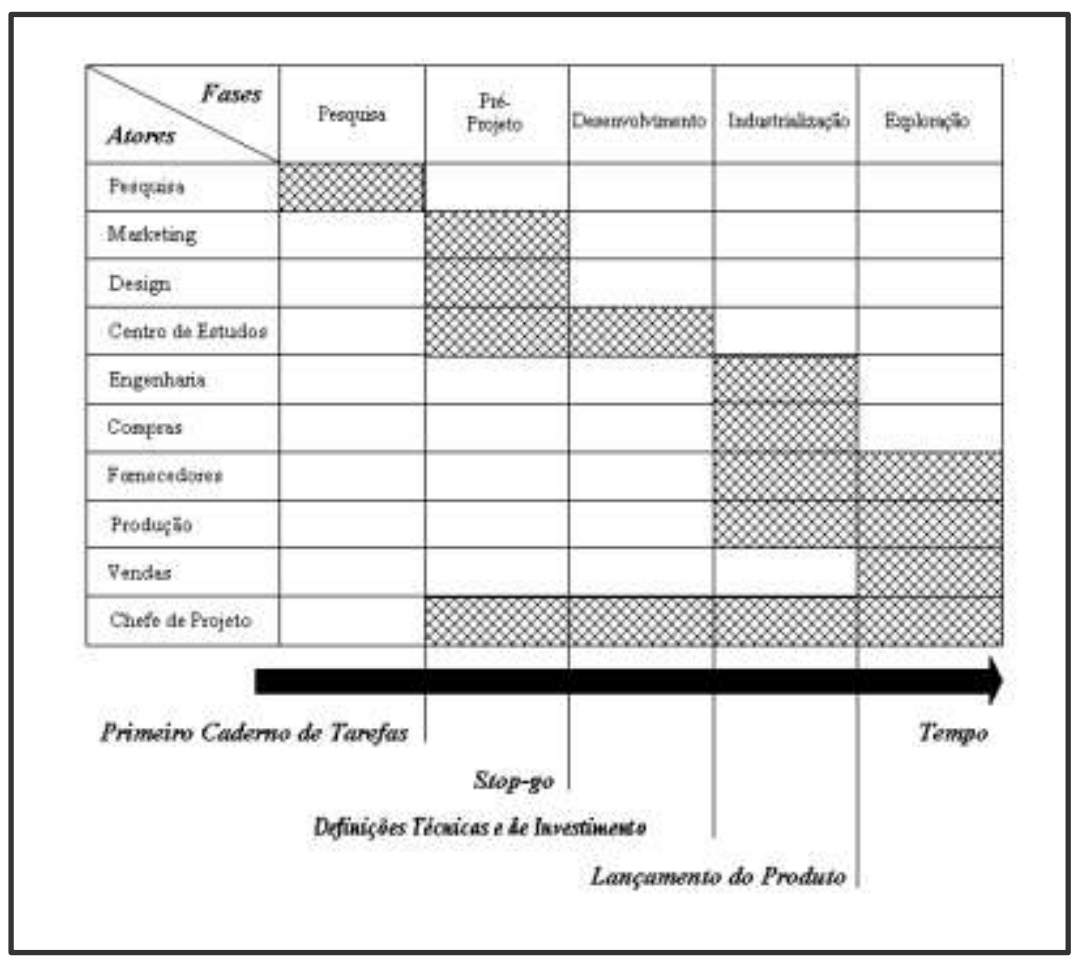


Figura 2 - Estrutura de Projeto Fast-Track da Indústria Automobilística

Todavia, a mudança do modelo de racionalização dos processos produtivos e as fortes pressões pela redução dos custos e do tempo de execução dos projetos destinados à produção do automóvel fez acompanhar uma profunda alteração em seu método de gestão, sendo identificados basicamente dois caminhos:

a) um primeiro, que traz a aplicação da idéia de concorrência ou simultaneidade, isto é, dos princípios de engenharia simultânea a um número crescente de projetos internos da FIASA;

b) e, um outro caminho, segundo o qual o sucesso dos novos projetos do processo de fabricação da FIASA, estariam cada vez menos associados à tradicional visão burocrática, mecânica, permanente, ao rigor do planejamento e ao emprego das ferramentas tradicionais de controle, mas sim à flexibilidade da organização, à autonomia dos atores e à qualidade do sistema de relações interpessoais e de comunicações do novo projeto da Fábrica Racionalizada.

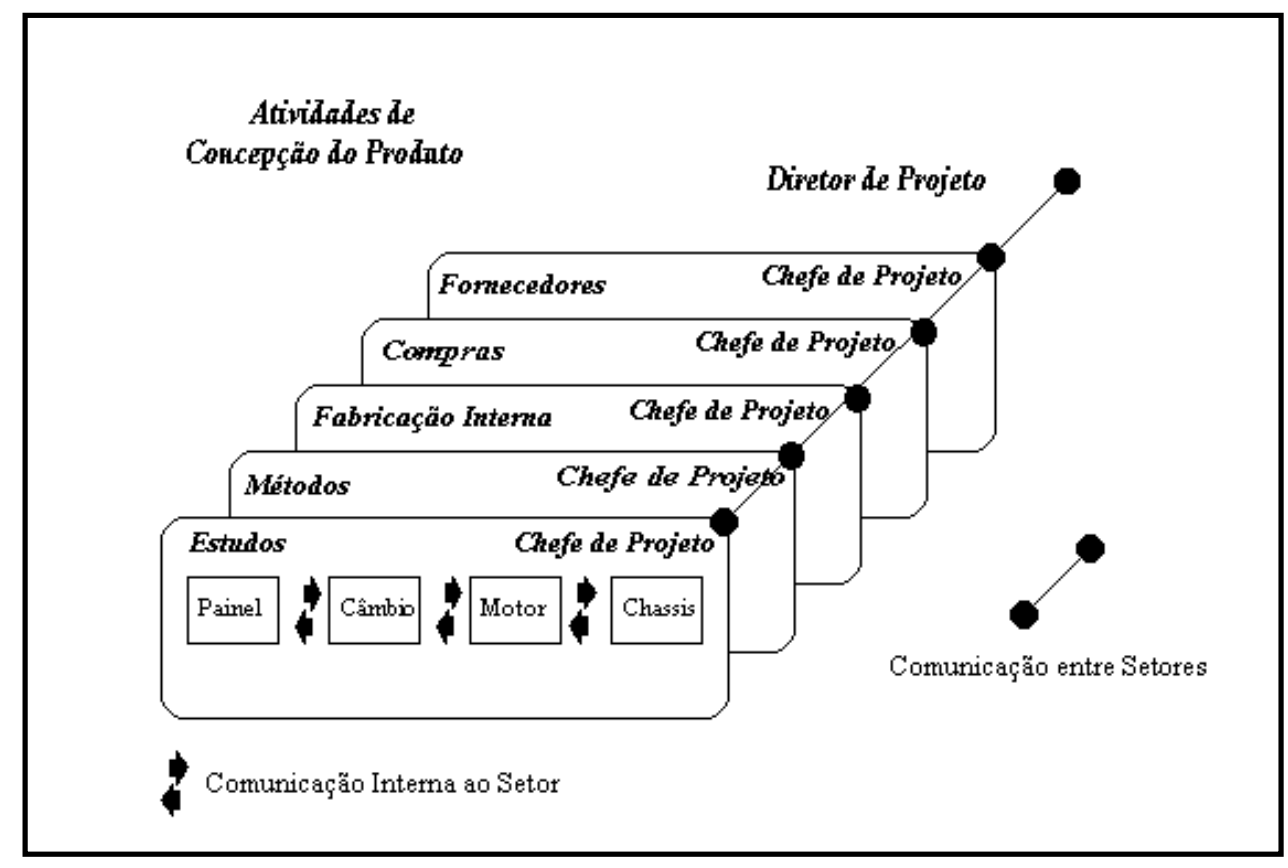

Fonte: MIDLER, C. 1993.

Figura 3 - Estrutura de Projeto de Desenvolvimento Concorrencial na Indústria Automobilística

Essas transformações acabam por trazer toda uma série de modificações e desdobramentos para a organização da empresa, que doravante exploraremos de modo mais detalhado.

Na nova gestão dos projetos da FIASA, de modo idêntico a outras experiências pós-fordistas de ponta na indústria automobilística, a estrutura tradicional de tipo fast-track é substituída por uma forma concorrencial, na qual as tarefas básicas são definidas e trabalhadas de forma simultânea por 
diversos atores, e a comunicação passa a ser realizada tanto através dos chefes de projeto como pelas instâncias intermediárias de cada grupo de funções ou atores (vide Figura 3).

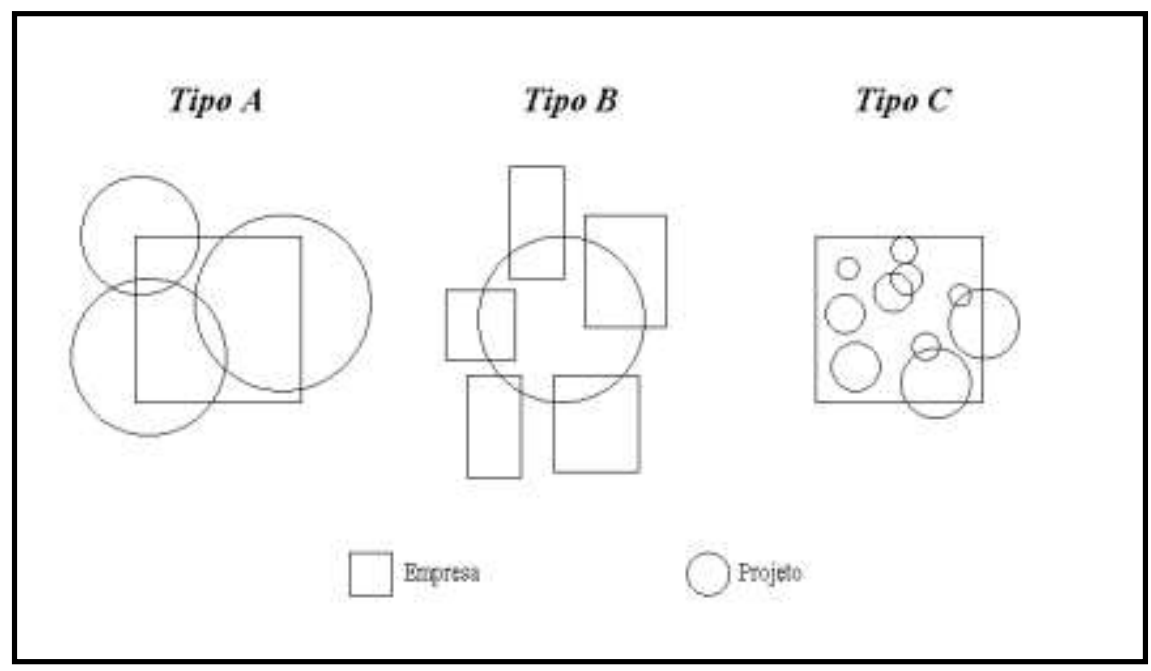

Fonte: GIARD, V. \& MIDLER, C. In: ECOSIP, 1993.

Figura 4 - Tipologia de Projetos segundo o Ponto de Vista Econômico

Assim, com esse novo modelo, a FIASA quebra o princípio mecanicista da ordem seqüencial de realização de um projeto, em detrimento ao princípio social do envolvimento dos participantes, ainda que de forma desordenada, desde o seu início até a sua consecução. Em relação a esse último ponto, a idéia de concorrência implica o envolvimento, o engajamento, e o exercício do diálogo e da consulta no projeto desde o seu início, e o seu resultado maior seria a rapidez na sua conclusão. Nesse sentido, a sua decorrência seria vista no uso de equipes pluridisciplinares de trabalho voltadas para o tratamento de questões de ordem estratégica, de reinvenção dos processos, de uso de sistemas informáticos ou tecnologias de informação e de condutas de mudança, fortemente marcadas pela consideração intensiva dos aspectos humanos nessas atividades.

Ainda, em relação à fábrica brasileira, na medida em que ela se caracteriza como uma empresa orientada ao projeto, essa nova forma concorrencial de gestão estaria na ordem, ou seria expressa como o resultado da convergência de três visões distintas da gestão de projetos, sendo elas caracterizadas tal como:

a) uma atividade econômica;

b) uma relação voltada para o cliente externo;

c) uma atividade de organização da empresa.

$\mathrm{Na}$ primeira visão, sob o ponto de vista econômico, essa visão desencadeia um perfil de desenvolvimento de projeto, segundo o qual a empresa dominante mobiliza outras empresas na manutenção dos projetos essenciais à sua existência, bem como a sua decomposição em outros subprojetos, constituindo uma rede ou cadeia de produção. Na Figura 4, o tipo A apresentado caracteriza bem essa relação. O desenvolvimento da gestão orientada à projeto deslancha um tipo de 
relação que impõe uma organização destinada a desenvolver a integração entre os atores internos, e desses com os fornecedores. De modo contrário à forma tradicional de gestão - na qual a montadora assumia um papel de determinante na concepção e executante final dos componentes, cabendo às fornecedoras somente a realização dos projetos isolados dos componentes -, nesse novo sistema de gestão essas empresas participam ativamente da definição dos projetos dos componentes. Certas tarefas de desenvolvimento do projeto são transferidas para fora das empresas automobilísticas, criando uma verdadeira integração e um sistema reticular entre os fornecedores e a montadora. Um excelente exemplo dessa nova relação seria o conceito de empresa-rede desenvolvida pela FIASA.

Em relação à segunda visão, aquela da relação voltada para o cliente externo, essa pressupõe um tipo de projeto no qual as suas atividades são centradas em um cliente potencial, como forma de garantir um controle maior sobre os custos da realização da produção, bem como sobre sua efetiva redução. Na FIASA, essa visão de gestão seria vista nos movimentos de focalização da produção sobre o cliente, destacando-se como exemplos, o movimento da clientocracia, bem como as políticas de melhoramento competitivo, voltadas para a satisfação do cliente e a logística integrada da empresa. Sua maior intenção estaria na ordem da superação da rigidez do modelo organizacional anterior com vistas a desenvolver em todos os seus níveis uma ampla capacidade de delegação da responsabilidade decisória, uma redução dos níveis hierárquicos, bem como a transformação da cadeia burocrática taylorista/fordista em um novo modelo mais voltado para o envolvimento amplo e difuso de todos os dependentes nas iniciativas de melhoramento contínuo, bem como na integração da rede de fornecedores e dos concessionários em um desenho organizacional coletivo de parceria sinérgica.

Isto posto, as maiores conseqüências dessa nova visão estariam no desenvolvimento de uma empresa horizontal (por processos) caracterizada pelo amplo controle de todas as atividades fundamentais, bem como as suas relações à montante (fornecedores) e à jusante (concessionários e cliente final) do processo produtivo.

Por fim, no tocante à terceira visão, aquela relacionada com a atividade de organização da empresa em relação à gestão orientada a projeto, percebe-se que grande parte do setor automobilístico, bem como a fábrica brasileira voltam-se para o desenvolvimento da forma de gestão de projeto/produção horizontalizada (Tiger Teams Organizations). Nesse tipo de gestão de projeto, tal como exposto na Figura 1, o controle dos projetos dá-se de forma externalizada à empresa, ou seja, os atores que trabalham sobre o projeto são fisicamente e institucionalmente removidos de suas estruturas funcionais de trabalho para serem agrupados em uma equipe ou forçatarefa externa atuando sob o comando do diretor de projeto durante todo o período de sua intervenção. Desse modo, o projeto ganha um caráter temporário e autônomo em relação à estrutura da empresa. 
Por outro lado, essa configuração horizontalizada de projeto, além de sua natureza flexível e autônoma, teria como conseqüência maior todo um conjunto de ações, assim definidas como meta-regras, que implicariam em uma complexa transformação da organização da empresa.

Em relação à FIASA, percebe-se que seu projeto de reestruturação assume essa forma de gestão de projetos/produção horizontalizada constituindo-se o seu campo de desenvolvimento por excelência. Assim, a firma estrutura seu processo produtivo sob a ótica da empresa orientada à projeto, e cujo maior resultado seria a organização por setores da empresa de equipes de projetos com diretor e chefes específicos trabalhando em dedicação exclusiva a esses. Contudo, a maior consequiência dessa forma de organização nos moldes da Tiger Teams Organizations bem como o conjunto de suas meta-regras para o processo produtivo da empresa, seria a concepção do processo de fabricação, isto é, da linha de montagem, sob a ótica da manufatura celular, que nesse caso, é assumida pelas unidades tecnológicas elementares, ou simplesmente UTEs.

Sob esse enfoque, a manufatura celular assume a forma dominante da organização de todo o processo de produção, constituindo-o como um conjunto de unidades ou elementos operativos e, assim, as UTEs, como o resultado desse processo, passam a ser vistas como unidades que governam todo o processo de produção da fabricação do automóvel (Figura 5).

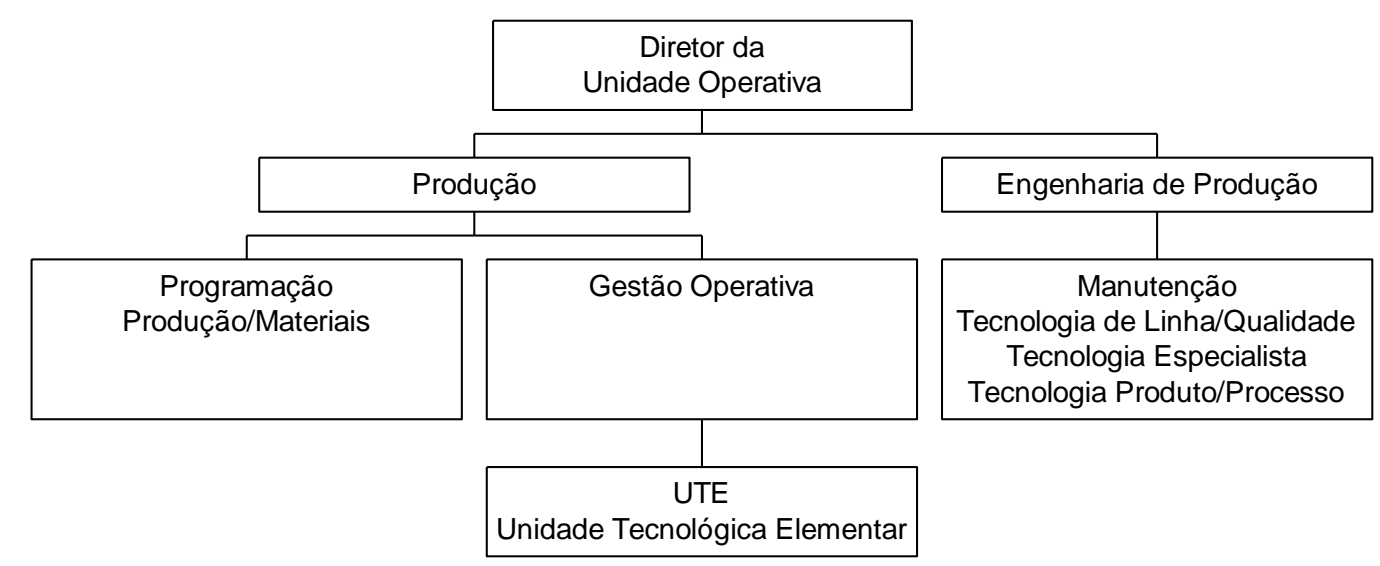

Fonte: CARDOSO, 2002

Figura 5 - Estrutura da Unidade Operativa

Ainda, a principal função da UTE estaria na ordem da gestão de um subsistema técnico relativo a um processo homogêneo produtor dos componentes de um produto final do processo produtivo. Embora vista como uma derivação das antigas equipes de trabalho da tradição taylorista/fordista da Fiat italiana - muito embora o fordismo capenga de Betim jamais estivesse relegado a essa prerrogativa -, a UTE assume um poder de decisão e de coordenação das atividades focalizadas no âmbito de seu processo, sendo centrais as atividades de controle da qualidade dos produtos a ela repassados à montante do processo produtivo, a administração dos equipamentos, bem como a organização do trabalho na célula. Ainda, a UTE goza da prerrogativa da autonomia 
necessária sobre a gestão dos recursos humanos e técnicos em seu interior, uma vez que ela é a principal responsável pela a tomada de decisões nos processos de anormalidades e de variabilidades do processo produtivo. Por outro lado, essa autonomia também articula-se com a essência dos princípios do melhoramento contínuo do sistema JIT, uma vez que o aproveitamento da experiência cotidiana na célula de trabalho torna-se uma condição necessária para a criação de um movimento sistemático e contínuo de aprimoramento do seu processo de trabalho.

No tocante ao aspecto externo da produção, as UTEs teriam uma grande implicação na relação da fábrica com as empresas subcontratadas, provocando nessas uma profunda modificação na sua estruturação. A organização celular da produção passa a exigir uma relação de cooperação ativa ente a Fábrica e os seus empregados e fornecedores. Se no fordismo capenga a cooperação ativa era um privilégio de determinados segmentos da empresa, em geral pertencentes ao topo da hierarquia da empresa e de certos fornecedores, agora, com esse novo modelo essa relação muda, tende a se flexibilizar, consolidando um padrão mais cooperativo e ativo de relacionamento entre a empresa, os empregados e os fornecedores dos outros níveis da cadeia produtiva.

Por outro lado, olhando um outro aspecto do processo produtivo, sob a influência do sistema JIT conjugado com o TQM, as UTEs forçam e impõem uma importante modificação nas relações da Fábrica com as firmas subcontratadas ao processo de fabricação. Se anteriormente o processo de subcontratação funcionava como parte da estratégia de descentralização da produção que visava transferir riscos para as empresas subcontratadas, além de eliminar parte dos focos de conflito com a força de trabalho, agora, com as UTEs, a relação de subcontratação torna-se um elemento de suma importância para o desenvolvimento do processo produtivo, passando a requerer um processo cada vez mais sistemático e de aprimoramento permanente junto aos fornecedores. Sob esse enfoque do JIT/TQM, o comportamento inovativo/aprimorativo torna-se central. A preocupação constante com a qualidade gera uma situação de tensão permanente entre os atores internos e externos à produção, notabilizando-se como uma condição necessária para a consolidação de uma dinâmica produtiva sob a ótica qualificante.

\section{ABSTRACT}

This paper aims to analyze the changes in the activity of project management in a Brazilian enterprise of the auto branch since the post-fordist restructuring process.

Key words: Production Management, Project Management, Meta-Rules, Post-Fordism 


\section{Referências}

CARDOSO, L. A. Aprés-fordisme et participation. restructuration productive contemporaine et nouvelle rationalisation du travail dans l'industrie automobile brésilienne. Lille, Sept. 2002.

CLARK, K. B.; HAYES, R. H.; WHEELRIGHT, S. C. Dynamic manufaturing: creating the learning organization. New York: The Free Press, 1988.

ECOSIP. Pilotages de projete et entreprises. Paris : Econômica, 1993.

JOLIVET, F. Grands projets, auto-organisation, méta-règles: vers de nouvelles formes de management de grands projets. Gestion 2000, n. 2, avr. 1993.

JOLY, M.; MULLER, J. De la gestion de projet au management par projet. Paris : AFNOR Gestion, 1994.

MIDLER, Christophe. L'Auto qui n'existait pas: management des projets et transformation des entreprises. Paris : Intereditions, 1993. 